\title{
Mestres e Doutores em Contabilidade no Brasil: Uma Análise dos Componentes Pedagógicos de sua Formação Inicial
}

\author{
Master's and Doctoral Degree Programs to Train Accounting \\ Professors in Brazil: An Analysis of the Pedagogical \\ Components of their Initial Training
}

\author{
Camilla Soueneta Nascimento Nganga ${ }^{1 *}$ \\ Reiner Alves Botinha ${ }^{2}$ \\ Gilberto José Miranda ${ }^{1}$ \\ Edvalda Araujo Leal ${ }^{2}$
}

${ }^{1}$ Universidade de São Paulo. ${ }^{2}$ Universidade Federal de Uberlândia

\begin{abstract}
A educação contábil no Brasil passa por transformações oriundas, principalmente, da expansão do ensino superior, do aumento do número de programas de pósgraduação em contabilidade e da adoção das normas internacionais de contabilidade. A Lei das Diretrizes e Bases da Educação Nacional (LDB) dispôs que a preparação para a docência deve acontecer em nível de pós-graduação, prioritariamente, em programas de mestrado e doutorado. Diante do exposto, a presente pesquisa tem como objetivo principal identificar quais são os componentes curriculares de formação pedagógica sistematizada presentes nos cursos de PósGraduação stricto sensu brasileiros em Ciências Contábeis. A análise dos cadernos de indicadores dos referidos programas, disponibilizados pela Coordenação de Aperfeiçoamento de Pessoal de Nível Superior (CAPES), revelou um baixo número de disciplinas relativas à formação de professores oferecidas pelos cursos de mestrado e doutorado em Ciências Contábeis, bem como uma diversidade no que tange à oferta do Estágio Docência nesses cursos. Esse panorama reforça o fato de que os referidos programas têm como foco a formação de pesquisadores, com baixa atenção para a consolidação dos saberes pedagógicos dos futuros professores.
\end{abstract}

Palavras-chave: Formação docente; Currículo, Habilidades de ensino, Competências docentes, Ciências contábeis.

The teaching of accounting in Brazil is experiencing transformations, mainly due to the expansion of higher education, the increased number of graduate accounting programs and the adoption of international accounting standards in the country. The Law on National Education Guidelines and Bases (LDB) requires that college professors must have graduate-level training, with priority on master's and doctoral programs. In this context, the main objective of this study was to identify the curriculum components for systematized teacher training that are present in Brazilian graduate programs in accounting. The analysis of the indicators of the referred programs, provided by the Office to Improve University Personnel (CAPES) of the Ministry of Education, revealed a low number of disciplines related to training of future professors offered by the master's and doctoral programs in accounting, as well as wide variation in the offer of graduate teaching assistant positions. This panorama reflects the fact these programs are mainly focused on the development of researchers, with little attention paid to instilling teaching skills in future professors.

Keywords: Teacher training, Curriculum, Teaching skills, Teacher competencies, Accounting.

*Contacto: camillasoueneta@usp.br

ISSN: 1696-4713

rinace.net/reice/

revistas.uam.es/reice
Recibido: $\quad 3$ de noviembre 2014

$1^{\text {a }}$ Evaluación: 1 de marzo 2015

$2^{\text {a }}$ Evaluación: 15 de mayo 2015

Aceptado: 22 de junio 2015 


\section{Introdução}

Considerando o contexto atual da docência no ensino superior, podendo-se citar, por exemplo, a expansão do número de matrículas, a diversidade discente nas salas de aula e presença maciça de aparelhos eletrônicos (tablets, smartfones, etc,), diversas discussões têm sido implementadas sobre as práticas pedagógicas adotadas em sala de aula pelos professores (Andere e Araújo, 2008; Benedito, Ferrer e Ferreres, 1995; Brezezinski, 2002; Laffin, 2001; Miranda, 2010; Slomski, 2007; Zabalza, 2004; Vasconcelos, 2009). De uma forma geral, os professores que tiveram a sua formação em cursos de bacharelado revelam carência no que se refere às condições necessárias para a atuação como docentes, tendo em vista que esses tiveram pouco ou nenhum contato com componentes curriculares relativos a conteúdos didático-pedagógicos durante a sua formação (Comunelo, Espejo, Boese e Lima, 2012).

A qualificação requerida para a atuação do docente sempre foi marcada pelo domínio do conteúdo em sua área de atuação, enquanto o conhecimento das práticas pedagógicas não era considerado como relevante. Atualmente, diversas mudanças estão ocorrendo no contexto da educação superior, o que gera a reflexão e o debate sobre o tema. A educação contábil no Brasil passa por transformações oriundas, principalmente, da expansão do ensino superior, do aumento do número de programas de pós-graduação em contabilidade e da adoção das normas internacionais de contabilidade (Miranda, Casa Nova e Cornacchione, 2013).

Os cursos de Pós-Graduação Stricto Sensu têm como objetivos formar docentes e pesquisadores. A Lei das Diretrizes e Bases da Educação Nacional (LDB) dispôs, dentre as exigências para a atividade docente no ensino superior, que a preparação para o magistério superior deve acontecer em nível de pós-graduação, prioritariamente, em programas de mestrado e doutorado. Importante destacar que a referida Lei não aborda, em seu escopo, a exigência de uma carga horária em componentes curriculares de cunho didático-pedagógico.

Nesse sentido, a preparação para a docência prevê o desenvolvimento das seguintes competências: formação prática; formação técnico-científica; formação pedagógica; e formação social e política (Andere e Araújo, 2008). Assim, os cursos de pós-graduação deveriam oferecer componentes curriculares que possibilitassem aos discentes o acesso tanto à pesquisa quanto aos saberes pedagógicos, os quais são importantes na formação dos docentes para a sua atuação no processo de ensino-aprendizagem. No entanto, devido ao "silêncio" da legislação que trata do assunto, pouco se sabe sobre as possibilidades ofertadas na Pós-Graduação Stricto Sensu.

Diante desse cenário, identifica-se o seguinte problema de pesquisa: quais os componentes curriculares de formação pedagógica sistematizada estão presentes nos cursos de pós-graduação stricto sensu em Ciências Contábeis brasileiros?

A pesquisa tem como objetivo principal identificar quais são os componentes curriculares de formação pedagógica sistematizada ofertados nos cursos de pósgraduação stricto sensu em Ciências Contábeis brasileiros. Os resultados de pesquisas anteriores apontam que os programas de pós-graduação em contabilidade estão direcionados, preponderantemente, para a formação de pesquisadores (Andere e Araujo, 2008; Miranda, 2010). 
Espera-se que a pesquisa proporcione reflexões sobre as práticas pedagógicas oferecidas aos docentes, bem como indagações sobre os componentes curriculares presentes nessa área. As justificativas para tal investigação referem-se às mudanças ocorridas recentemente no cenário educacional (expansão dos cursos de graduação e pósgraduação) e na Contabilidade (adoção dos padrões internacionais) e à suposta ausência da formação pedagógica na Pós-Graduação em Ciências Contábeis.

\title{
1. Expansão dos Programas de Pós-Graduação em Ciências Contábeis Stricto Sensu
}

Os aspectos iniciais que permeiam os cursos de pós-graduação do Brasil surgiram com a Lei 4.024/61, que determina, dentre diversos fatores, quais programas de pós-graduação poderiam ser oferecidos aos candidatos que tivessem concluído o curso de graduação e obtido o respectivo diploma (Peleias, Segreti, Silva e Chirotto, 2007). Para complementar a Lei supracitada, o Parecer $n^{\circ} 977$ de 1965, do Conselho Federal de Educação, apresentou os três motivos fundamentais que exigiram o estabelecimento de cursos de pós-graduação:

\begin{abstract}
(...) formar professorado competente que possa atender à expansão quantitativa do nosso ensino superior garantindo, ao mesmo tempo, a elevação dos atuais níveis de qualidade; estimular o desenvolvimento da pesquisa científica por meio da preparação adequada de pesquisadores; e assegurar o treinamento eficaz de técnicos e trabalhadores intelectuais do mais alto padrão para fazer face às necessidades do desenvolvimento nacional em todos os setores. (BRASIL, 1965, p. 3)
\end{abstract}

O mesmo parecer classifica os cursos de pós-graduação em duas modalidades distintas: $o$ lato sensu e o stricto sensu, sendo os cursos lato sensu representados pelos cursos de especialização, e os cursos stricto sensu, pelos cursos de mestrado e doutorado. Segundo Silva e Costa (2013, p. 2), "o pressuposto central é de que os cursos de natureza stricto sensu têm por finalidade formar docentes para exercício de atividades correntes exercidas em uma instituição de educação superior".

Em relação à área de Ciências Contábeis, observa-se o pioneirismo da Universidade de São Paulo no que se refere aos programas de pós-graduação stricto sensu, sendo essa a primeira instituição a ofertar o curso de mestrado em contabilidade no ano de 1970 e, posteriormente, em 1978, o curso de doutorado em contabilidade (Cunha, Cornacchione e Martins, 2008). Também, em 1978, foi criado o segundo curso de mestrado em contabilidade na Pontifícia Universidade Católica (PUC).

Posteriormente, somente a partir da década de 90, surgiram novos programas de PósGraduação Stricto Sensu em Ciências Contábeis, conforme demonstrado no quadro 1. Nessa época, diversas são as razões que motivaram o crescimento dos programas de pósgraduação, dentre elas, pode-se destacar a criação da Lei 9.394/1996 (LDB), a qual estabeleceu que pelo menos um terço do corpo docente das instituições de ensino superior deverá apresentar titulação mínima de doutorado.

A expansão do ensino superior no contexto nacional também foi outro fator que determinou o crescimento dos programas de pós-graduação. Na área contábil, em 1991, existiam 262 cursos superiores na área de Contabilidade; já em 1998, 406 cursos e, em 2008, havia 985 cursos de Ciências Contábeis, conforme dados do Ministério da Educação (2013). Sobre esse contexto, Comunelo e outros (2012) apontam a preocupação 
com a qualidade da educação contábil e remetem aos cursos de pós-graduação a responsabilidade pela formação dos professores e pesquisadores.

O quadro 1 registra a relação dos programas de pós-graduação stricto sensu em Ciências Contábeis existentes no Brasil, por Instituição de Ensino Superior (IES), no ano de 2013.

Quadro 1. Programas de pós-graduação stricto sensu em Ciências Contábeis em 2013

\begin{tabular}{ccclcc}
\hline N. & IES & UF & \multicolumn{1}{c}{ PROGRAMA } & CONCEITO & INÍ́CIO \\
\hline 1 & USP & SP & Mestrado/Doutorado & 6 & 1970 \\
2 & PUC/SP & SP & Mestrado & 3 & 1978 \\
3 & UFRJ & RJ & Mestrado & 4 & 1998 \\
4 & UNIFECAP & SP & Mestrado & 4 & 1999 \\
5 & UNISINOS* & RS & Mestrado/Doutorado & 4 & 1999 \\
6 & UNB & DF & Mestrado/Doutorado & 4 & 2000 \\
7 & FUCAPE & ES & Mestrado/Doutorado & 4 & 2001 \\
8 & UFSC & SC & Mestrado/Doutorado & 4 & 2003 \\
9 & FURB & SC & Mestrado/Doutorado & 4 & 2005 \\
10 & UFPR & PR & Mestrado & 3 & 2005 \\
11 & USP/RP* & SP & Mestrado/Doutorado & 4 & 2005 \\
12 & UERJ & RJ & Mestrado & 3 & 2006 \\
13 & UFBA & BA & Mestrado & 3 & 2007 \\
14 & UFMG & MG & Mestrado & 4 & 2007 \\
15 & UFPE & PE & Mestrado & 3 & 2007 \\
16 & UFC** & CE & Mestrado & 3 & 2009 \\
17 & UFES*** & ES & Mestrado & 3 & 2010 \\
18 & UFU*** & MG & Mestrado & 3 & 2013 \\
\hline
\end{tabular}

Fonte: CAPES-Coordenação de Aperfeiçoamento do Pessoal de Nível Superior (2013).

Nota: *Doutorado aguardando homologação CNE (Conselho Nacional de Educação); ** Mestrado acadêmico em Administração e Controladoria; ****Mestrado aguardando homologação CNE.

É oportuno mencionar que 10 programas $(55,56 \%)$ estão disponibilizados na região Sudeste, representando essa a maior área de concentração, enquanto, na Região Norte, não há nenhum Programa de Pós-Graduação Stricto Sensu em Contabilidade.

A evolução do número de programas Stricto Sensu em Ciências Contábeis, no Brasil, apresenta um crescimento mais expressivo a partir do ano de 1998, ou seja, dentre os programas existentes na atualidade, apenas dois existiam em 1998, com a oferta de dois cursos de mestrado e um, de doutorado.

Peleias e outros (2007, p. 30) ressaltam que a expansão dos programas de pós-graduação stricto sensu em Ciências Contábeis trouxe algumas consequências positivas para a área: o aumento da produção científica de contabilidade no panorama brasileiro; a criação da Associação Nacional de Programas de Pós-Graduação em Ciências Contábeis (ANPCONT); e a alteração da designação da área "Administração e Turismo", da CAPES, para área de "Administração, Ciências Contábeis e Turismo".

\section{Formação Pedagógica Sistematizada}

Considerando a ampliação do acesso ao ensino superior ocorrido nos últimos anos, os processos de inclusão, os avanços da tecnologia e a globalização do conhecimento, bem como a diversidade de alunos que, atualmente, chegam às universidades impõem ao docente uma nova postura, qual seja: 
[...] o professor seja muito mais do que um animador, competente para expor, cativando a atenção do aluno. Ele precisará adquirir a necessária competência para organizar situações de aprendizagem em que as interações entre aluno e conhecimento se estabeleçam de modo a desenvolver as capacidades de leitura e interpretação do texto e da realidade, comunicação, análise, síntese, crítica, criação, trabalho em equipe, etc. (Laffin, 2001, p. 62)

Nesse cenário, Silva e Costa (2013) definem a formação docente como "um processo de desenvolvimento de competências que ocorre a partir de situações de aprendizagem que articulam o processo de ensino e de pesquisa como indissociáveis e que merecem atenção pelos agentes responsáveis pelo processo de formação” (p. 2).

Para Slomski (2007), tal formação deve estar ancorada nos três pilares do conhecimento: ensino, pesquisa e extensão. Na integração entre os três fatores listados, há também a produção, a troca e a disseminação de conhecimento, sinalizando essa indissociabilidade uma atividade reflexiva do profissional docente. A autora entende que a multiplicidade de situações vividas pelo professor, em meio ao trabalho docente, alcança diversos papeis, tais como: o processo de ensino-aprendizagem; o processo de gestão da sala de aula; o ato de planejar e preparar as atividades docentes; a escolha de estratégias de ensino; o olhar atento para as diferenças e experiências trazidas pelos alunos; dentre outros.

A esse respeito, Mellowki e Gauthier (2004), ao destacarem a complexidade da profissão docente, utilizam as palavras de Barlow (1999, pp. 145-156), as quais ilustram com clareza os atributos necessários ao docente ideal.

O ensino é uma profissão tão paradoxal que quem a exerce deveria possuir, ao mesmo tempo, as qualidades de estrategista e de tático de um general do exército; as qualidades de planejador e líder de um dirigente de empresa; a habilidade e a delicadeza de um artesão; a destreza e a imaginação de um artista; a astúcia de um político; o profissionalismo de um clínico geral; a imparcialidade de um juiz; a engenhosidade de um publicitário; os talentos, a ousadia e os artifícios de um ator; o senso de observação de um etnólogo; a erudição de um hermeneuta; o charme de um sedutor; a destreza de um mágico e muitas outras qualidades cuja lista seria praticamente ilimitada. (p. 543)

Nesse sentido, a docência é composta por várias atividades que precisam ser pensadas e construídas ao longo da formação e durante o exercício da profissão docente (Slomski, 2007). Para muitos autores (Andere e Araújo, 2008; Laffin, 2001; Slomski, 2007; Vasconcelos, 2009), o pilar “Ensino”, do tripé “Ensino, Pesquisa e Extensão”, não tem recebido a devida atenção.

Vasconcelos (2009) salienta que profissionais em contabilidade que construíram uma carreira profissional de sucesso são selecionados para ministrar aulas em cursos superiores sem que tenham preparo pedagógico para essa atividade. Isso significa dizer que esse profissional, na maioria das vezes, evidencia ampla experiência de mercado, com cursos de pós-graduação (modalidade lato sensu, na área de negócios, chamados de MBA - Master in Business Administration), mas não possui uma formação pedagógica, social e política necessária para o exercício da profissão docente (Vasconcelos, 2009). Nesse sentido, o profissional dorme contador e acorda professor... (Lima et al., 2015).

Andere e Araújo (2008, p. 95) também afirmam que profissionais contábeis com experiência no mercado vão atuar na carreira acadêmica com o objetivo de difundir os conhecimentos adquiridos no decorrer de sua vida profissional. Assim, considera-se necessário refletir que o domínio do conteúdo específico e do conteúdo didáticopedagógico por parte dos professores é requisito primordial para o processo de formação dos futuros profissionais de contabilidade, não sendo suficiente somente o primeiro, 
porque o domínio do conteúdo específico, por si só, não garante ao professor a capacidade de ensinar (Benedito, Ferrer e Ferreres, 1995; Brezezinski, 2002; Miranda, 2010; Vasconcelos, 2009; Zabalza, 2004).

Em termos de legislação, cabe destacar que a Lei das Diretrizes e Bases da Educação Nacional estabelece que "a preparação para o exercício do magistério superior far-se-á em nível de pós-graduação, prioritariamente, em programas de mestrado e doutorado". Destaca-se o uso do termo "prioritariamente" no texto da referida Lei, o qual quer dizer que a preparação dos docentes dar-se-á de forma prioritária, e não obrigatória, nos programas de pós-graduação stricto sensu (mestrado e doutorado). Assim, depreende-se que essa preparação poderá ser realizada por meio de programas de pós-graduação classificados como lato sensu.

O Ministério da Educação, juntamente com a CAPES, por meio da Portaria MEC/CAPES n ${ }^{\circ} 76 / 2010$, estabeleceu que o Estágio de Docência seja obrigatório aos alunos bolsistas CAPES/DS, e opcional, aos demais. Esse mesmo dispositivo normativo define o Estágio de Docência como "parte integrante da formação do pós-graduando, objetivando a preparação para a docência, e a qualificação do ensino de graduação”.

Segundo o Art. 18 do referido dispositivo (DOU, 2010), para o desenvolvimento do estágio docência, torna-se necessário, dentre os critérios ressaltados, para o programa que tem os cursos de mestrado e doutorado, que a obrigatoriedade caiba ao doutorado e, ao que possuir apenas o nível de mestrado, essa obrigatoriedade será transferida para o mestrado. A duração mínima para os programas de mestrado será de um semestre e a máxima, de dois semestres. Já para os programas de doutorado, a duração mínima será de dois semestres e máxima, de três semestres. Ressalta-se que a carga horária máxima do estágio docência deverá ser de 4 horas semanais.

Diante do exposto, assinala-se que a CAPES, com a instituição do estágio docência, passa a interferir (positivamente) sobre a formação de professores universitários, na medida que atinge os programas stricto sensu. No entanto, Patrus e Lima (2012) questionam se os programas de pós-graduação têm condições de conceber um estágio docência que contribua efetivamente para a formação pedagógica dos participantes.

No contexto da Contabilidade, alguns estudos com foco na formação docente em Ciências Contábeis também foram desenvolvidos (Comunelo et al., 2012; Miranda, 2010; Miranda, Casa Nova e Cornacchione, 2012; Nossa, 1999). A seguir são evidenciados os principais achados.

Nossa (1999) parte do entendimento de que "o professor não deve estar preocupado apenas em passar para o aluno os conhecimentos que sabe, mas fazer o aluno aprender a aprender e para isso, é preciso estar preparado" (p. 1). Em sua pesquisa, o autor esclarece que, em decorrência da demanda por professores, ocasionada pela expansão dos cursos de graduação em Ciências Contábeis, muitos profissionais têm se inserido na academia sem a devida preparação, tendo as instituições se preocupado muito com número e pouco, com a qualidade.

Miranda (2010) visou a identificar quais disciplinas e conteúdos didático/pedagógicos são oferecidos nos programas de pós-graduação stricto sensu em Ciências Contábeis, no Brasil, e quais dimensões da formação pedagógica predominam nesses programas. Os resultados da pesquisa apontaram que, dos dezoito programas de mestrado e três de doutorado analisados, apenas em dois cursos de mestrado existia a obrigatoriedade em se 
cursarem disciplinas didático-pedagógicas e com carga horária inferior às demais disciplinas. $\mathrm{O}$ autor também aponta que, quanto aos demais programas, a maioria deles apresentava essas disciplina de maneira optativa ou eletiva, permitindo a possibilidade de o aluno escolher em cursá-las ou não, o que, consequentemente, propiciava a conclusão do curso de mestrado e doutorado sem que, necessariamente, o aluno tivesse cursado disciplinas de natureza didático-pedagógica.

Tais resultados convergem para os estudos da área de educação, os quais abordam que, nos desenhos dos programas de pós-graduação existentes no País, a preparação para a docência superior, quando há, restringe-se à oferta da disciplina Metodologia do Ensino Superior, mas que, na prática, não ultrapassa 60 horas de atividades (Anastasiou, 2003; Masetto, 2003).

Com relação à percepção dos coordenadores e discentes dos programas de pósgraduação, Andere e Araújo (2008) constataram que os programas de pós-graduação em Ciências Contábeis "estão direcionados (...) para a formação de pesquisadores com conhecimentos teóricos e específicos da área contábil, voltados para a pesquisa científica" (p. 91).

Quanto às competências específicas dos docentes, percebem-se diferentes abordagens. Miranda (2010) verificou que o domínio do conteúdo específico é o mais encontrado nas ementas das disciplinas dos programas de pós-graduação, enquanto que o domínio na área pedagógica, bem como o exercício da dimensão política, não são contemplados com a importância que deveriam ter na formação dos professores de contabilidade.

A relevância da preparação didática foi discutida na pesquisa empírica desenvolvida por Miranda e outros (2012), que buscou identificar os saberes predominantes dos docentes tidos como professores-referência, segundo o olhar dos alunos de graduação em Ciências Contábeis de uma universidade pública. Como resultado da pesquisa, os autores verificaram que o conhecimento didático e a metodologia de ensino se sobrepõem ao domínio do conteúdo e às suas experiências, o que denota a necessidade de preparação didática para a prática docente.

Já Comunelo et al. (2012) buscaram identificar qual a contribuição dos Programas de Pós-Graduação stricto sensu, em nível de mestrado em contabilidade, na formação de professores e pesquisadores. Os autores constataram que os seis Programas de PósGraduação (PPGs) analisados formaram profissionais para a docência, com base no fato de que, após a conclusão do mestrado, de 115 egressos, 104 lecionam em instituições de ensino, evidenciando ainda mais a necessidade de preparo especial para o exercício da docência.

Silva, Kreuzberg e Rodrigues Júnior (2015), com o proposito de avaliar o desempenho dos programas de pós-graduação brasileiros de Ciências Contábeis, concluíram que uma das principais limitações enfrentadas pela Pós-Graduação nessa área é a "forte endogenia na formação dos docentes quanto pesquisadores, implicando na necessidade de ampliação dos doutorados nesta área pelo país" (p. 134). Os autores destacaram que os programas de pós-graduação pesquisados são norteados, principalmente, para a publicação científica, ou seja, privilegiam a pesquisa.

Em síntese, os estudos acima discutidos apresentaram reflexões sobre a formação de professores para o exercício do magistério superior em cursos de Ciências Contábeis. Neles, fica clara a necessidade de uma formação pedagógica sistematizada para o 
exercício da docência. Assim, na presente pesquisa, pretendem-se evidenciar quais componentes curriculares pedagógicos que poderiam compor tal formação estão presentes nos cursos de pós-graduação stricto sensu em Ciências Contábeis brasileiros.

\section{Aspectos Metodológicos}

O presente estudo é delineado, quanto aos objetivos, como descritivo, pois visa a descrever as características de uma dada população ou fenômeno, para, então, estabelecer relações entre as variáveis (Gil, 2002). Já a abordagem metodológica adotada na presente pesquisa é a qualitativa.

A pesquisa é de caráter censitária, uma vez que contempla os dezoito programas de pósgraduação stricto sensu (acadêmicos) em Ciências Contábeis existentes no Brasil em 2013, apresentados no quadro 1. É importante salientar que não foram investigados os programas de caráter profissional, por se tratarem de programas voltados para a formação de profissionais para o mercado de trabalho, não sendo, portanto, escopo do presente estudo.

Em relação aos procedimentos de coleta e análise de dados, a investigação se classifica como documental, tendo sido a pesquisa realizada com dados secundários. Foram acessados os documentos constantes nos cadernos de indicadores divulgados na página eletrônica da CAPES (DI: Disciplinas, LP: Linhas de Pesquisa e PO: Proposta do Programa). Essas informações foram complementadas por outras coletadas nas páginas eletrônicas dos programas, como, por exemplo, a informação do caráter das disciplinas (se optativa/eletiva ou obrigatória) e outras informações sobre os programas que ainda estavam em processo de homologação, uma vez que esses programas ainda não tinham documentos disponibilizados no portal eletrônico da CAPES. Durante a coleta de dados, buscou-se verificar se:

a. o programa oferta disciplinas condizentes com a formação pedagógica do aluno de pós-graduação stricto sensu, bem como sua obrigatoriedade;

b. o conteúdo das ementas das disciplinas de formação pedagógica ofertadas, as referências bibliográficas apresentadas e as respectivas cargas-horárias;

c. o programa oferece o Estágio Docência ou programas correlatos; e

d. se existem projetos e/ou grupos de pesquisa na área de Educação e Pesquisa Contábil evidenciados pelo programa.

Inicialmente, foi feito um levantamento das disciplinas destinadas à formação pedagógicas ofertadas pelos programas pesquisados e sua obrigatoriedade, conforme item (a).

Para alcançar o proposto no item (b), uma vez identificadas as disciplinas de formação pedagógica constantes no documento de disciplinas ofertadas no ano, buscaram-se analisar as ementas, os tópicos das disciplinas e as referências bibliográficas a serem utilizadas. Quanto às referências bibliográficas, a análise teve como foco verificar se o aluno está recebendo formação, especificamente, com relação ao ensino em contabilidade, no que tange às práticas pedagógicas, ou se ele está recebendo essa formação de modo a integrar tanto leituras da área de educação, como leituras da área de contabilidade. 
Em relação ao item (c), a análise foi dirigida com a finalidade de identificar se existem programas de estágio que preparam o aluno de maneira prática para a docência, sob acompanhamento dos professores dos programas, o que também pode ser um ponto importante na formação dos mestrandos e doutorandos. Quanto ao item (d), o propósito foi verificar se há projetos e/ou grupos de pesquisas que envolvam alunos do programa em pesquisas sobre Educação e Pesquisa Contábil.

As informações levantadas foram analisadas e discutidas à luz do quadro teórico delineado. Cumpre destacar que a sistemática de análise dos conteúdos abordados nas ementas das disciplinas ligadas à formação docente (conforme exposto no quadro 3) foi semelhante àquela utilizada no estudo de Miranda (2010).

\section{Análise e Discussão dos Resultados}

\subsection{Disciplinas concernentes à formação pedagógica}

A partir do levantamento das informações referentes aos programas de pós-graduação em Ciências Contábeis, aqui denominados apenas de "programas", a análise documental foi realizada. Destaca-se que a classificação em disciplinas obrigatórias e optativas ou eletivas foi realizada com base no caderno de indicadores da CAPES, e as disciplinas que não foram encontradas na página eletrônica dos programas foram classificadas como "não mencionado". O quadro 2 exibe as disciplinas ligadas à formação docente oferecidas pelos programas analisados.

Quadro 2. Disciplinas ligadas à formação docente

\begin{tabular}{clcc}
\hline IES & \multicolumn{1}{c}{ DISCIPLINA } & CARGA HORÁRIA & \multicolumn{1}{c}{ TIPO } \\
\hline \multirow{2}{*}{ FURB } & $\begin{array}{l}\text { Metodologia do Ensino em Contabilidade } \\
\text { Tecnologias da Informação aplicadas ao } \\
\text { Ensino Superior }\end{array}$ & 45 & Optativa / Eletiva \\
PUC/SP & Metodologia do Ensino da Contabilidade & 45 & Optativa / Eletiva \\
UERJ & Metodologia do Ensino Superior & 45 & Optativa / Eletiva \\
UFBA & Metodologia do Ensino Superior & 51 & Optativa / Eletiva \\
UFC & Teoria e Prática na Docência em Gestão & 48 & Não mencionado \\
UFPR & Metodologia do Ensino em Contabilidade e & 45 & Optativa / Eletiva \\
UFRJ & Finanças & & Obrigatória \\
UFSC & Metodologia do Ensino Superior & 30 & Optativa / Eletiva \\
UFU & Metodologia do Ensino Superior & 45 & Optativa / Eletiva \\
UNIFECAP & Didática do Ensino de Contabilidade & 60 & Optativa / Eletiva \\
UNISINOS & Metodologia do Ensino Superior & 48 & Optativa / Eletiva \\
& Metodologia do Ensino na Contabilidade & 120 & Obrigatória* \\
USP & Tecnologia da Educação & 120 & Optativa / Eletiva \\
\hline
\end{tabular}

Fonte: Dados da Pesquisa.

Nota: *Obrigatória apenas para o programa de mestrado.

Com base nas informações disponibilizadas no quadro 2 , foi possível verificar que, dentre os 18 programas de pós-graduação stricto sensu em Ciências Contábeis existentes, somente 12 deles oferecem disciplinas ligadas à formação docente. Verificou-se, ainda, que há a preponderância do termo "metodologia", conforme também apontado por Miranda (2010). Dentre as 14 disciplinas identificadas nos programas como sendo disciplinas que possibilitam a formação docente, duas são obrigatórias nas instituições 
UFRJ e USP, o que denota que os alunos, necessariamente, receberão essa formação durante o desenvolvimento do curso.

Nessa óptica, cabe resgatar o questionamento de Patrus e Lima (2012), "e a formação da dimensão pedagógica dos mestres e doutores?” (p. 12). Os autores ressaltam que os programas de pós-graduação stricto sensu dirigem foco maior para a formação do pesquisador, ficando esse foco distante, de certa forma, da formação pedagógica. A pequena oferta de disciplinas pedagógicas obrigatórias nos programas de pós-graduação em contabilidade diagnosticada neste estudo corrobora com os achados indicados por Patrus e Lima (2012) e por Silva, Kreuzberg e Rodrigues (2015).

Em relação à carga horária das disciplinas, foi identificado que somente a UFRJ oferece a disciplina "Metodologia do Ensino Superior", com carga horária de 30 horas, apresentando as disciplinas oferecidas por outras instituições uma carga horária maior ou igual a 45 horas, o que difere dos resultados divulgados por Miranda (2010), cujo estudo aponta que a maioria das disciplinas identificadas tinha carga menor que 45 horas. Isso sugere ter havido mudanças nesse período, uma vez que ambas as pesquisas foram realizadas na Pós-Graduação Stricto Sensu em Contabilidade.

Verificou-se também que, somente nas instituições UFU e USP, são oferecidas disciplinas (três disciplinas) com carga horária igual ou maior que 60 horas, ou seja, conforme mencionado anteriormente, faz parte do panorama geral dos cursos de pósgraduação brasileiros que eles se limitam a oferecer disciplinas de cunho optativo que não ultrapassam 60 horas de atividades (Anastasiou, 2003; Masetto, 2003).

Os programas da FUCAPE, UNB, UFMG, UFES e UFPE não oferecem disciplinas ligadas à formação docente, seja de forma obrigatória ou optativa. Nessas circunstâncias, os interessados por esse tipo de formação têm que ir em busca de cursos de pósgraduação de outras áreas, como a área de Educação.

A esse respeito, Andere e Araújo (2008), por meio de entrevistas com discentes e coordenadores dos cursos de Pós-Graduação Stricto Sensu em Contabilidade, identificaram que a formação técnico-científica é a que apresentou uma maior relevância para os respondentes, os quais se mostraram convictos de ser essa a área mais incentivada pelos programas. Silva, Kreuzberg e Rodrigues Júnior (2015) identificaram uma forte relação da publicação de trabalhos científicos dos professores em conjunto com os alunos dos programas de pós-graduação. Nesse sentido, os autores alertam para a preocupação excessiva com a produtividade, o que poderá gerar limitações na formação do estudante de pós-graduação para o exercício da docência.

\subsection{Conteúdo das disciplinas de formação pedagógica}

A formação dos docentes não deve se concentrar, prioritariamente, na concepção técnico-teórica e de pesquisa. Assim, os programas de pós-graduação stricto sensu devem contribuir para a melhoria da formação didático-pedagógica de seus alunos (Miranda et al., 2013; Oliveira et al., 2009).

O quadro 3 demonstra os conteúdos presentes nas ementas das disciplinas analisadas, com base em classificação já utilizada por Miranda (2010). Cumpre salientar que as ementas foram extraídas, exclusivamente, dos cadernos de indicadores da CAPES, com base nas informações disponibilizadas pelos respectivos programas. 
Quadro 3. Conteúdos abordados nas ementas das disciplinas ligadas à formação docente

\begin{tabular}{lcccccc}
\hline & FURB & PUC-SP & UERJ & UFBA & UFC & UFPR \\
\hline Ensino Superior & & $\mathrm{X}$ & $\mathrm{X}$ & $\mathrm{X}$ & $\mathrm{X}$ & $\mathrm{X}$ \\
Ensino de Contabilidade & & $\mathrm{X}$ & $\mathrm{X}$ & & & $\mathrm{X}$ \\
Currículo & & $\mathrm{X}$ & & & $\mathrm{X}$ & $\mathrm{X}$ \\
Profesor & & $\mathrm{X}$ & $\mathrm{X}$ & $\mathrm{X}$ & $\mathrm{X}$ & \\
Ensino/ Aprendizagem & $\mathrm{X}$ & $\mathrm{X}$ & $\mathrm{X}$ & $\mathrm{X}$ & $\mathrm{X}$ \\
Planejamento & $\mathrm{X}$ & $\mathrm{X}$ & & $\mathrm{X}$ & & $\mathrm{X}$ \\
Avaliação & $\mathrm{X}$ & $\mathrm{X}$ & & & $\mathrm{X}$ \\
Técnicas de Ensino & $\mathrm{X}$ & $\mathrm{X}$ & $\mathrm{X}$ & $\mathrm{X}$ & & \\
Recursos Didáticos & & $\mathrm{X}$ & & $\mathrm{X}$ & & $\mathrm{XSP}$ \\
\hline & $\mathrm{UFRJ}$ & $\mathrm{UFSC}$ & $\mathrm{UFU}$ & $\mathrm{UNIFECAP}$ & $\mathrm{UNISINOS}$ & $\mathrm{USP}$ \\
\hline Ensino Superior & $\mathrm{X}$ & $\mathrm{X}$ & $\mathrm{X}$ & $\mathrm{X}$ & & $\mathrm{X}$ \\
Ensino de Contabilidade & $\mathrm{X}$ & & $\mathrm{X}$ & $\mathrm{X}$ & $\mathrm{X}$ & $\mathrm{X}$ \\
Currículo & & $\mathrm{X}$ & $\mathrm{X}$ & $\mathrm{X}$ & $\mathrm{X}$ & $\mathrm{X}$ \\
Profesor & & $\mathrm{X}$ & $\mathrm{X}$ & $\mathrm{X}$ & $\mathrm{X}$ & $\mathrm{X}$ \\
Ensino/ Aprendizagem & $\mathrm{X}$ & $\mathrm{X}$ & & $\mathrm{X}$ & $\mathrm{X}$ & $\mathrm{X}$ \\
Planejamento & & $\mathrm{X}$ & $\mathrm{X}$ & $\mathrm{X}$ & $\mathrm{X}$ & $\mathrm{X}$ \\
Avaliação & $\mathrm{X}$ & $\mathrm{X}$ & $\mathrm{X}$ & $\mathrm{X}$ & $\mathrm{X}$ \\
Técnicas de Ensino & & $\mathrm{X}$ & $\mathrm{X}$ & $\mathrm{X}$ & $\mathrm{X}$ \\
Recursos Didáticos & & $\mathrm{X}$ & $\mathrm{X}$ & & & $\mathrm{X}$ \\
\hline
\end{tabular}

Fonte: Dados da pesquisa.

Diante dos conteúdos das ementas, constatou-se que os temas "Ensino Superior", "Professor", "Ensino / Aprendizagem", "Planejamento", "Avaliação" e "Técnicas de Ensino" foram os mais evidenciados nas disciplinas voltadas para a formação de professores nos programas de pós-graduação em Ciências Contábeis.

Também pode-se observar, a partir da análise das referências bibliográficas, que a maioria dos programas de pós-graduação em Ciências Contábeis apresentou autores da área de educação, com exceção da instituição USP (disciplina "Metodologia do Ensino na Contabilidade”), que registrou um maior número de autores da área de contábil. Diante disso, pode-se tecer inferências sobre dois aspectos. Primeiramente, que disciplinas referenciadas com maior enfoque na Educação podem auxiliar na formação dos pósgraduandos, fornecendo a esses elementos teóricos alicerçados em saberes didáticopedagógicos, o que é positivo nesse processo de formação docente, uma vez que os autores possuem formação nessa área (Pimenta e Anastasiou, 2002).

O segundo aspecto revela que poucos pesquisadores oriundos da contabilidade têm interesse pelos temas relacionados à educação e à pesquisa contábil. Miranda e outros (2013) apontaram um baixo percentual de publicações sobre esse tema realizadas pelos doutores em Ciências Contábeis. Os autores destacam a necessidade de ações que fortaleçam a pesquisa sobre Educação Contábil no Brasil, bem como a valorização das publicações na área.

Já Slomski (2007) preconiza que o professor necessita não apenas ministrar sua aula, mas participar de outras atividades, tais como: (i) auxiliar na elaboração do projeto pedagógico; (ii) garantir uma boa aprendizagem dos alunos (e bons resultados podem ser obtidos com a utilização de diferentes técnicas sugeridas pela literatura sobre saberes docentes que são apresentados em uma disciplina referente à prática pedagógica); (iii) desenvolver formas de auxiliar os alunos com menores desempenhos; e (iv) participar das etapas de planejamento e avaliação e, ainda, no que tange ao desenvolvimento profissional. Isso significa que a atuação docente é ampla, visto que a formação oferecida 
no âmbito dos cursos de pós-graduação aos mestrandos e/ou doutorandos envolvendo as práticas pedagógicas poderão refletir na qualificação dos futuros docentes, que, consequentemente, serão responsáveis pelas diversas atividades acadêmicas requeridas na educação a nível superior.

\subsection{Oferta de estágio docência e programas correlatos}

Os saberes experienciais também são importantes na formação docente, notadamente, a experiência em sala de aula. Nesse sentido, o quadro 4 traz as informações sobre estágio docência e componentes similares apresentadas pelos programas pesquisados.

Quadro 4. Estágio docência

\begin{tabular}{clcc}
\hline IES & DISCIPLINA & CARGA HORÁRIA & TIPO \\
\hline FUCAPE & Estágio Docência & Não mencionado & Obrigatório (Bolsistas) \\
FURB & Estágio Docência & 60 & Obrigatório (Bolsistas) \\
UERJ & Estágio Docente & 15 & Obrigatório \\
UFBA & Tirocínio Docente Orientado & 68 & Obrigatório \\
UFC & Estágio Docente & 48 & Obrigatório (Bolsistas) \\
UFES & Monitoria Didática I e II & 30 & Optativa / Eletiva \\
UFMG & Estágio Docência & 60 & Obrigatório (Bolsistas) \\
UFPE & Prática de Ensino em Contabilidade & 30 & Optativa / Eletiva \\
UFPR & Estágio docência & 30 & Optativa / Eletiva \\
UFRJ & Estágio Docência & 45 & Não mencionado \\
UFSC & Estágio de docência & 30 & Optativa / Eletiva \\
UFU & Estágio Docência & 15 & Obrigatório \\
UNB & Prática de Ensino & Obrigatório \\
UNIFECA & Programa de monitoria para TCC & Não mencionado & Não mencionado \\
P & Varia de acordo & Obrigatório (Bolsistas) \\
UNISINOS & Estágio de Docência & com a disciplina & Optativa / Eletiva \\
& PAE: Programa de Aperfeiçoamento & Não mencionado & Opto \\
USP & de Ensino & Go (Cada) & Optativa / Eletiva \\
& Monitoria Didática I e II & Não mencionado & Não mencionado \\
USP/RP & PAE: Programa de Aperfeiçoamento & de Ensino &
\end{tabular}

Fonte: Dados da pesquisa.

$\mathrm{O}$ quadro 4 revela que somente as instituições de ensino UERJ, UFBA, UFU e UNB implementaram estágio docência e programas relacionados com caráter obrigatório. Cabe ressaltar que, ainda que a UNB ofereça a disciplina "Prática de Ensino" como obrigatória, essa dispõe de apenas 15 horas de carga horária. As instituições FUCAPE, FURB, UFC, UFMG e UNISINOS disponibilizam o estágio docência com caráter obrigatório, porém somente para os alunos bolsistas. Já as demais IES incluem esses componentes como optativos. Na PUC/SP, não foi possível verificar a obrigatoriedade ou não dessas atividades, pois não foram localizadas quaisquer informações, nesse sentido, na página eletrônica do programa.

Torna-se oportuno pontuar a diversidade desse componente curricular entre as instituições pesquisadas: há diferentes nomenclaturas, diferentes cargas-horárias dedicadas à prática, bem como obrigatoriedade diversa. Além disso, foram observadas informações incompletas a respeito do componente. Tal situação pode gerar subjetivismo no entendimento da forma como o programa propõe o estágio docente aos alunos. 
Diante do exposto, destaca-se a relevância do Estágio Docência como um meio de estabelecer a preparação para o exercício do magistério superior no nível de pósgraduação, como exposto no Art. 18 da Portaria MEC/CAPES n ${ }^{\circ}$ 76/2010. A esse respeito, Andere e Araújo (2008) entendem que o Estágio Docência visa a estabelecer a integração dos programas de pós-graduação com a graduação, com o objetivo de propiciar aos alunos de mestrado e doutorado não somente a teoria pertinente à pedagogia, mas também a vivência prática no que diz respeito ao processo de ensinoaprendizagem. Nas atividades práticas propiciadas por meio dos estágios docência, podese institucionalizar um processo de aprendizagem experiencial e mediado pela ação, em que o pós-graduando vivencie e tenha a oportunidade de participar ativamente da prática docente (Silva e Costa, 2013).

Lapini (2012) salienta que o professor precisa estar integrado tanto com os aspectos relacionados ao saber ensinar, quanto com os aspectos relacionados à prática, conforme propõe o estágio docência. De acordo com o quadro 4, das 18 instituições pesquisadas, 11 (FURB, UERJ, UFBA, UFC, UFPR, UFRJ, UFSC, UFU, UNIFECAP, UNISINOS, USP) já propõem a integralização das disciplinas teóricas de formação docente com a prática docente por meio do estágio docência e programas correlatos. É importante destacar que a prática é importante, mas por si só não garante o efetivo preparo do professor para o exercício da docência. A existência de disciplinas e conteúdos teóricos poderá evitar que a formação pedagógica seja realizada como base na tentativa e no erro, o que culminaria em uma formação espontânea.

\subsection{Grupos e/ou projetos de pesquisas com ênfase em Educação Contábil}

Com relação aos grupos e/ou projetos de pesquisas com ênfase em educação contábil, o quadro 5 arrola as entidades que possuem grupos e/ou projetos de pesquisas na área de ensino, o que contribui para o contato do estudante com o ensino e a aprendizagem, de forma a encontrar deficiências e oportunidades de melhoria da educação no ensino superior.

A participação do futuro professor em grupos e/ou projetos de pesquisa sobre educação contábil possibilita refletir sobre as práticas pedagógicas, conhecer a realidade de sala de aula, conhecer teorias sobre os processos de ensino-aprendizagem, métodos de avaliação, estratégias de ensino, entre outros temas caros à docência. Esse contato contribui, sem dúvida, para sua formação pedagógica inicial, uma vez que torna familiar ao pesquisador temáticas que farão parte do seu cotidiano como professor.

Embora apenas o programa de pós-graduação em Ciências Contábeis da USP/SP apresente uma linha de pesquisa sobre "Educação Contábil", verifica-se que, das 18 instituições que constituem a amostra da pesquisa, 11 inserem grupos e/ou projetos de pesquisas na área de educação, o que representa cerca de $61 \%$ das instituições analisadas. Todavia, a pesquisa sobre educação contábil no Brasil ainda se mostre muito frágil, quando comparada a outras temáticas, conforme evidenciam Miranda et al. (2013). Torna-se necessário, portanto, o aumento de grupos e/ou projetos de pesquisas nessa área, de forma a propiciar condições para a discussão sobre a temática e a melhoria do ensino em contabilidade no Brasil. 
Quadro 5. Grupos e/ou projetos de pesquisa - educação

\begin{tabular}{|c|c|}
\hline IES & GRUPO DE PESQUISA E/OU PROJETOS \\
\hline FUCAPE & OE - Observatório da Educação. \\
\hline FURB* & Pesquisas em Gestão Universitária e Ensino Superior. \\
\hline $\mathrm{PUC} / \mathrm{SP}$ & Ensino da Contabilidade. \\
\hline UFBA & $\begin{array}{l}\text { Compreendendo os desafios do ensino de Contabilidade e Administração; } \\
\text { Determinantes do Desempenho Acadêmico e Estimativa da Fronteira de } \\
\text { Eficiência Educacional da UFBA; Grupo de Estudos e Pesquisa em Educação e } \\
\text { Responsabilidade Social Corporativa; Núcleo de Estudo e Pesquisa em Educação e } \\
\text { Responsabilidade Corporativa - NEPERC; Observatório FECAP de Pesquisa e } \\
\text { Educação Contábil; Observatório UFBA de Educação e Pesquisa Contábil; } \\
\text { Pesquisa sobre o ensino Contabilidade. }\end{array}$ \\
\hline UFMG & NUFI - Núcleo de Ensino, Pesquisa em Finanças e Contabilidade - UFMG. \\
\hline UFPR & $\begin{array}{l}\text { Ensino e Pesquisa em Contabilidade e Finanças: abordagens contemporâneas; } \\
\text { Intenção empreendedora dos alunos do curso de graduação em Ciências } \\
\text { Contábeis: Um Estudo Piloto com Alunos dos Cursos de Pós-Graduação Lato } \\
\text { Sensu da Universidade Federal do Paraná. }\end{array}$ \\
\hline UFSC & $\begin{array}{l}\text { Estudo da formação acadêmica dos pesquisadores de Ciências Contábeis no país; } \\
\text { Pesquisa e Ensino de Contabilidade, Administração e Finanças. }\end{array}$ \\
\hline UFU** & NEPAC - Núcleo de Ensino e Pesquisa em Administração e Contabilidade. \\
\hline UNB & Aprendizagem para a Contabilidade e Gestão em Educação a Distância. \\
\hline UNIFECAP & $\begin{array}{l}\text { Educação e trabalho para contadores e administradores; O perfil didático e } \\
\text { pedagógico de professores que atuam no curso de bacharelado em Ciências } \\
\text { Contábeis. }\end{array}$ \\
\hline USP & $\begin{array}{l}\text { Educação e pesquisa em contabilidade; Grupo de Estudos de Tecnologia da } \\
\text { Educação na Contabilidade - GETEC. }\end{array}$ \\
\hline
\end{tabular}

\section{Considerações Finais}

O presente estudo teve por objetivo identificar quais componentes curriculares de formação pedagógica sistematizada estão presentes nos cursos de pós-graduação stricto sensu em Ciências Contábeis brasileiros. Por meio de uma abordagem qualitativa, foi realizada a análise documental dos componentes curriculares de 18 programas de pósgraduação em Ciências Contábeis brasileiros, visando a identificar disciplinas, estágio docência e grupos e/ou projetos de pesquisas ligados à formação pedagógica presentes nesses programas.

Com base nos resultados alcançados, pode-se inferir que ainda é incipiente a presença de disciplinas ligadas à formação docente nos programas de pós-graduação stricto sensu em Ciências Contábeis do Brasil (do total de disciplinas oferecidas pelos programas, apenas 14 são ligadas à formação docente). E, quando tais disciplinas são oferecidas, essas são, em geral, de caráter optativo (apenas duas são obrigatórias) e carga horária igual ou inferior a 60 horas.

Diante dessa situação, pode-se concluir que os programas de pós-graduação em contabilidade continuam com foco na formação de pesquisadores, não sendo a formação docente suficientemente oferecida nos cursos de mestrado e doutorado da área. Esses achados corroboram com outras pesquisas que discutem a dissociação da pesquisa e do ensino na pós-graduação (Andere e Araujo, 2008; Lapini, 2012; Miranda, 2010; Patrus e Lima, 2012; Silva e Costa, 2013). Para Patrus e Lima (2012), diante dessa situação, a 
formação de docentes para atuar no ensino superior fica a cargo dos próprios professores, bem como dependem de ações pontuais de alguns programas de pósgraduação. No entanto, acaba por predominar a formação espontânea, adquirida na experiência.

Em relação ao Estágio Docência e programas voltados para a prática docente, ainda que a Portaria 76 de 2010 da CAPES, em seu $18^{\circ}$ Artigo, apresente direcionamentos para o desenvolvimento do Estágio Docência nos programas de pós-graduação, constatou-se grande heterogeneidade na forma como tais atividades estão sendo desenvolvidas nos cursos. Sobre a situação, é importante refletir e investigar se os programas de pósgraduação stricto sensu, em Ciências Contábeis, estão preocupados com a oportunidade de vivência prática da docência que o Estágio Docência oferece ou se a referida atividade foi instituída apenas como forma de atender a uma recomendação da CAPES.

Também, observou-se que apenas $39 \%$ das instituições (sete instituições) oferecem conjuntamente a disciplina de metodologia do Ensino Superior, o Estágio docência e Grupos e/ou Projetos de Pesquisa com ênfase em Educação Contábil. Esses achados evidenciam que há instituições preocupadas em oferecer a formação pedagógica nos programas de Mestrado e Doutorado, mas, ao mesmo tempo, chamam a atenção para a necessidade de os demais programas visualizarem seu papel de formadores de docentes e, assim, desenvolverem práticas similares, a fim de reforçar a qualidade na educação contábil no país. Da mesma forma, os mecanismos de avaliação da CAPES, que estão fortemente centralizados na pesquisa, deveriam contemplar aspectos relativos à formação para o exercício da docência de modo a estimular e valorizar o papel do professor em sala de aula.

É preciso salientar que os três componentes investigados nesta pesquisa são necessários na formação dos mestres e doutores para atuação em sala de aula em razão do contexto atual, ou seja, grandes modificações na forma de realizar e ensinar Contabilidade em virtude da adoção das Normas Internacionais de Contabilidade (as International Financial Reporting Standards) e grande expansão do ensino superior e da Pós-Graduação Stricto Sensu, notadamente, na área contábil, culminando em grande diversidade em sala de aula (diferentes gerações, raça, idade, etc), além da crescente complexidade na atuação docente.

Também, é importante enfatizar o "silêncio" da LDB 9.394/96 no tocante à formação docente para o exercício do magistério no ensino superior e o privilégio excessivo da pesquisa em detrimento do ensino constante nos mecanismos de avaliação da CAPES, visto que a maioria dos docentes da área contábil que está em sala de aula no Brasil não possui Pós-Graduação Stricto Sensu, ou seja, sua atuação é guiada, quase exclusivamente, pela experiência adquirida no mundo do trabalho, como exposto por Vasconcelos (2009), Andere e Araujo (2008) e Slomski (2007).

O desejável, portanto, seria que houvesse uma formação pedagógica sistematizada, com amparo legal e institucional, para o adequado preparo dos docentes para a atuação em sala de aula, pois, mesmo que as instituições ofereçam possibilidades de formação pedagógica, como as investigadas nesta pesquisa, é possível que a maioria dos mestres e doutores não passem por tais instâncias, pois o foco, normalmente, está na realização da tese ou dissertação, as quais direcionam as pesquisas e os cumprimentos de créditos. 
Espera-se que esta pesquisa possa contribuir com a literatura sobre a formação docente, ao evidenciar como os programas de pós-graduação stricto sensu estão tratando a formação didático-pedagógica de seus alunos. Quanto à prática, esta pesquisa contribui ao chamar a atenção para a adoção de métodos que auxiliem na formação pedagógica sistematizada dos alunos dos cursos de Mestrado e Doutorado, favorecendo o seu aprendizado para a carreira docente. Além disso, a pesquisa pode auxiliar a alunos, professores e pesquisadores sobre a temática, ao relacionar as instituições que têm dado maior prioridade sobre a Educação Contábil.

Como limites da pesquisa, destaca-se o fato de que determinados programas não disponibilizam, em suas páginas eletrônicas, todas as informações referentes aos componentes curriculares dos cursos.

Para investigações futuras, sugere-se a ampliação da amostra, considerando, também, outros cursos da área de negócios (como Administração e Economia), com o intuito de identificar as similaridades e as divergências que permeiam a formação docente nos cursos de mestrado e doutorado dessa área. Também, sugere-se a aplicação de questionários junto aos docentes e discentes dos programas de pós-graduação stricto sensu em Ciências Contábeis, com o intuito de verificar a percepção desses em relação à importância da formação docente.

\section{Agradecimentos}

Fundação de Apoio à Pesquisa do Estado de Minas Gerais (FAPEMIG)

\section{Referências}

Anastasiou, L.G.C. (2003). Ensinar, aprender e apreender processos de ensinagem. En L.G.C. Anastasiou e L.P. Alves (Orgs.), Processos de ensinagem na universidade (pp. 98-115). Joinville: Univille.

Andere, M.A. e Araújo, A.M.P. (2008). Aspectos da formação do professor de ensino superior de ciências contábeis: uma análise dos programas de pós-graduação. Revista de Contabilidade e Finanças, 19(48), 91-102.

Barlow, M. (1999). Le métier d'enseigner: essai de définition. París: Anthropos.

Benedito, V., Ferrer, V. e Ferreres, V. (1995). La Formación Universitaria a Debate. Barcelona: Publicaciones Universitat de Barcelona.

Comunelo, A.L., Espejo, M., Boese, S.B. e Lima, E.M. (2012). Programas de pós-graduação Stricto Sensu em contabilidade: sua contribuição na formação de professores e pesquisadores. Revista Enfoque - Reflexão Contábil, 31(1), 7-26.

Cunha, J.V.A., Cornacchione E.B. e Martins, G.A. (2008). Pós-graduação: o curso de doutorado em ciências contábeis da FEA/USP. Revista Contabilidade e Finanças, 19(48), 6-26.

Gil, A.C. (2002). Como elaborar projeto de pesquisa. São Paulo: Atlas.

Laffin, M. (2001). O professor de contabilidade no contexto de novas exigências. Contabilidade Vista e Revista, 12(1), 57-58.

Lapini, V.C. (2012). Panorama da formação do professor em Ciências Contábeis pelos cursos stricto sensu no Brasil. Dissertação de Mestrado. Universidade de São Paulo, Brasil. 
Lima, F, de Oliveira, A.C.L., Araújo, T.S. e Miranda, G.J. (2015). O choque com a realidade: dormi contador e acordei professor. REICE. Revista Iberoamericana sobre Calidad, Eficacia y Cambio en Educacion, 13(1), 49-68

Masetto, M.T. (2003). Competência pedagógica do professor universitário. São Paulo: Summus.

Mellouki, M. e Gauthier, C. (2004). O professor e seu mandato de mediador, herdeiro, intérprete e crítico. Educação e Sociedade, 25(87), 537-571.

Miranda, G.J. (2010). Docência universitária: uma análise das disciplinas na área da formação pedagógica oferecidas pelos programas de pós-graduação stricto sensu em Ciências Contábeis. Revista de educação e pesquisa em contabilidade, 4(2), 81-98.

Miranda, G.J., Casa Nova, S.P.C. e Cornacchione, E.B. (2012). Os saberes dos professoresreferência no ensino de contabilidade. Revista de contabilidade e finanças, 23(59), 142-153.

Miranda, G.J., Casa Nova, S.P.C. e Cornacchione, E.B. (2013). The accounting education gap in Brazil. China-USA Business Review, 12(4), 361-372.

Miranda, G.J., Santos, L., Casa Nova, S.P.C. e Cornacchione, E.B. (2013). Pesquisa em educação contábil: produção científica e preferências de doutores no período de 2005 a 2009. Revista Contabilidade e Finanças, 24(61), 361-372.

Nossa, V. (1999). Formação do corpo docente dos cursos de graduação em contabilidade no Brasil: uma análise crítica. Caderno de Estudos, 21, 1-24.

Oliveira, M.C.S., Melo, M., Oliveira, M.H. e Paiva, K. (2009). A Influência da "vivência docente" na formação e desenvolvimento de competências profissionais docentes: uma percepção de mestrandos em administração. En VV.AA (Eds.), Anais do encontro de ensino e pesquisa em administração e contabilidade (pp. 156-178). Porto Alegre: USP.

Patrus, R. e Lima, M.C. (2012). Entre a formação de professores e de pesquisadores nos programas de pós-graduação stricto sensu em administração: contradições e alternativas. En VV.AA (Eds.), Anais do encontro da ANPAD (pp. 347-353). Rio de Janeiro: ANPAD.

Peleias, I.R., Segreti, J.B., Silva, G.P. e Chirotto, A.R. (2007). Evolução do ensino da contabilidade no Brasil: uma análise histórica. Revista Contabilidade e Finanças, 4, 361-372.

Pimenta, S.G. e Anastasiou, L.G. (2002). Docência no ensino superior. São Paulo: Cortez.

Silva, A.B. e Costa, F. da. (2013). Itinerários para o desenvolvimento da competência docente na pós-graduação stricto sensu em administração. En VV.AA (Eds.), Anais do encontro da ANPAD (pp. 377-393). Rio de Janeiro: ANPAD.

Silva, T.P., Kreuzberg, F. y Rodríguez. M.M. (2015). Desempenho dos programas brasileiros de pós-graduação em contabilidade na tangente da pesquisa científica. REICE. Revista Iberoamericana sobre Calidad, Eficacia y Cambio en Educación, 13(1), 123-137.

Slomski, V.G. (2007). Saberes e competências do professor universitário: contribuições para o estudo da prática pedagógica do professor de ciências contábeis do brasil. Revista de Contabilidade e Organizações, 1(1), 87-103.

Vasconcelos, A.F. (2009). Professores em ciências contábeis: um estudo sobre as competências para o exercício da docência nos cursos presenciais no nordeste brasileiro. Dissertação de Mestrado. Programa Multi-institucional e Inter-Regional de Pós-Graduação em Ciências Contábeis (UNB, UFPB e UFRN), João Pessoa, PB, Brasil.

Zabalza, M.A. (2004). O Ensino Universitário, seu Cenário e seus Protagonistas. Porto Alegre: Artmed. 